\title{
Evaluation of population densities of the common wolf spider Pardosa agrestis (Araneae: Lycosidae) in Hungarian alfalfa fields using mark-recapture
}

\author{
BALÁZS KISS and FERENC SAMU \\ Department of Zoology, Plant Protection Institute, Hungarian Academy of Sciences, P.O. Box 102, H-1525 Budapest, Hungary; \\ e-mail: h2367sam@ella.hu
}

Key words. Pardosa agrestis, Araneae, Lycosidae, density estimation, mark-recapture, sampling method, pitfal traps, suction sampling, wolf spider, natural enemy

\begin{abstract}
The absolute population density of adult Pardosa agrestis (Westring, 1862), the dominant epigeic spider species in many arable lands in Central Europe, was quantified in two alfalfa fields using a multiple mark-recapture method. The resulting density estimates are presented together with catch data from simultaneously performed suction sampling and pitfall trapping. Two week long mark-recapture surveys were conducted in August 1995 and 1996 using grids of $11 \times 11$ live-catching pitfall traps covering a square area of $400 \mathrm{~m}^{2}$ in the first, and $900 \mathrm{~m}^{2}$ in the second survey. The trap checking and marking procedure, using individual codes, was done daily. Over 5,000 spiders were marked in the two surveys. The number of spiders caught varied greatly between days. The recapture rate was also variable, ranging between 5-19\%. Recaptured animals moved considerable daily distances, marked animals left the area of the trapping grid within a few days. Population sizes were estimated for 3 day time windows during which period the population could be considered closed. Spider densities were calculated from the estimated abundances and the capture area, which consisted of the grid area plus a boundary strip calculated from the estimated movement ranges of spiders. The resulting densities were close to 2 males and 1 female per $\mathrm{m}^{2}$ in the first, and 4.5 males and 4.5 females per $\mathrm{m}^{2}$ in the second experimental site. Suction sampling caught very few adult individuals and gave unsatisfactory data for statistical comparison. Live catching pitfall trap catches did not correlate with the derived mark-recapture density estimates across the short time windows, but for the entire trapping sessions the catches were consistent with the density estimates.
\end{abstract}

\section{INTRODUCTION}

The estimation of population density is important for a wide range of ecological studies concerning spiders. Many different methods have been applied to assess spider population density (reviewed in Sunderland et al, 1995). Suction sampling in many respects is the most effective, and can be generally recommended for density estimation of spiders (e.g. Duffey, 1980; Dinter, 1995), on the other hand, this method was shown to fail with highly mobile and visually sensitive (Ford, 1978) species, such as wolf spiders (Lycosidae) (Samu et al., 1997). In spite of the many criticisms it has received, pitfall trapping is still widely used even in quantitative ecological studies as an alternative to suction sampling, because of easy operation and continuous catching. Pitfall traps measure only the relative abundance of spiders (Southwood, 1978), because catches are not only a function of population density, but also of activity and speciesspecific catchability (Sunderland et al., 1995).

Wolf spiders are a major group of predators in agricultural systems world-wide. In Central Europe one species, Pardosa agrestis, is by far the most dominant epigeic spider in many arable cultures, such as cereals or alfalfa (Samu et al., 2000). Even though this spider species is obviously abundant (Samu et al., 1996b; Tóth \& Kiss, 1997), there have been no attempts to estimate its population densities. Additionally, studies to asses densities of other wolf spiders in agricultural areas have been unsuccessful so far (Dinter, 1995; reviewed in Sunderland \& Topping, 1995). To quantify the density of adults of $P$. agrestis populations we conducted two intensive markrecapture (MR) surveys in parallel with pitfall trapping and suction sampling in two alfalfa fields. The latter two methods were applied with "regular" sampling effort we used for longer term ecological studies. The MR study was conducted to overcome the methodological difficulties of density estimation and to provide base-line density figures, to which sampling results of the traditional methods could be compared.

\section{MATERIAL AND METHODS}

\section{Sampling sessions}

The two MR surveys were run in 3 year old alfalfa fields. Survey A was carried out in 1995, from the 30th of July to the 13th of August, in a 10 ha alfalfa field situated at the NW border of Budapest. Last cutting took place one week before the start of trapping; the height of the alfalfa was ca. $20 \mathrm{~cm}$. Survey B was conducted in 1996, from the 3rd to the 17th of August, in a 59 ha alfalfa field $150 \mathrm{~km}$ to the South from Budapest, in Tolna County, Hungary. This field was cut three weeks before the survey, and the alfalfa was $50 \mathrm{~cm}$ tall. No pesticides were applied to any of the fields in the year of the survey.

One hundred and twenty-one live-catching pitfall traps were installed in both fields in a $11 \times 11$ grid with $2 \mathrm{~m}$ (survey A) and $3 \mathrm{~m}$ (survey B) trap distances, covering a square area of $20 \times 20 \mathrm{~m}$ in the first and $30 \times 30 \mathrm{~m}$ in the second survey. The nearest trap was $30 \mathrm{~m}$ (survey A) and $100 \mathrm{~m}$ (survey B) from the border of the field. The traps were made of plastic cups (diameter $=75 \mathrm{~mm}$ ) with a removable insert. Live pitfall trapping in each survey represented a sampling effort of 1815 trap days. Pitfall trapping with the same type of plastic cups as in the MR study, containing preservative liquid ( $40 \%$ ethylene glycol 
and detergent) was conducted in both fields with 12 and 7 traps, representing 210 and 105 trap days sampling effort in A and B surveys, respectively. Traps were emptied once at the end of the sampling session. Suction sampling with a hand-held device with a $0.01 \mathrm{~m}^{2}$ nozzle (Samu \& Sárospataki, 1995a) was conducted 3 times during each survey period (1995: 31/07, 9/08, $13 / 08 ; 1996: 6 / 08,13 / 08,17 / 08)$. This represented a sampling effort of 54 and 30 samples of $0.1 \mathrm{~m}^{2}$ (10 nozzle applications each) in survey A and B, respectively.

\section{Marking procedure}

The live-catching traps were emptied daily. Newly captured $P$. agrestis adults received a semi-individual code consisting of 3 "TRINAT" enamel paint dots (positioned on the dorsal surface of the spider, at the back of the prosoma and the entire area of the opisthosoma). The trap where the spider was caught was coded by the position of the dots, and the date of trapping was coded by colour. Recaptured animals received a supplementary dot, thus their code became absolutely individual. The marking was done without narcotization. After the marking and recording procedure the animals were released $0.5 \mathrm{~m}$ from the trap where they were caught.

\section{Abundance and density estimation}

The data from the two sexes and from the two surveys were treated separately in all analyses. Estimation of population abundance was performed with the computer program "Capture" (White et al., 1982), which includes capture-recapture models for closed populations sampled over multiple markingcapturing occasions. Using the multivariate model selection procedure of Capture (Otis et al., 1978) the "Mt" model was chosen to be the most appropriate. The Mt model avoids the assumption of constant capture probabilities of the Petersen-Lincoln type models (Seber, 1982) by allowing capture probabilities to vary by time. Since a closed population is a basic assumption of the Mt model, using the test provided by Capture, we tested for population closure in time windows of varying length. For later analyses the maximum window width, where closure held for the majority of the windows, was selected. The cases where the hypothesis of closure was rejected and the cases where no recapture event occurred were excluded from statistical analyses. The mean of estimations was calculated by weighting the estimated results with the number of recapture events in the time windows (Otis et al., 1978).

To determine population density, we used the estimate of population size from the above procedure, and we needed an estimate of the size of the area where the animals belonging to the population occurred. We defined this area as the area of the trap grid, plus a border strip from where spiders had an opportunity to move into the trap grid over the length of the time window applied. The width of this strip was the radius of the estimated range the spiders covered over that period. The range of movement was calculated by interpolating from the fitted regression line between time to recapture and distances covered by the re-

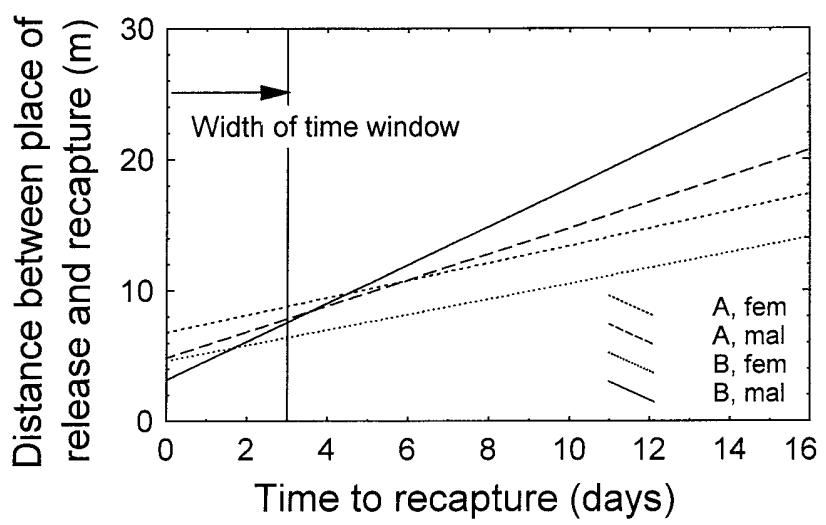

Fig. 1. Fitted regression lines between the distances covered (between the place of release and recapture) and the time elapsed until the recapture of male and female $P$. agrestis in the two surveys.

captured animals (Fig. 1) to the movement range value at the width of the applied time window.

\section{Comparison of sampling methods}

No statistical comparison was made between MR density estimates and suction samples due to the very low number of $P$. agrestis adults caught by the latter method. Live-trapping pitfall catches and derived MR density estimates for time windows were compared. No such temporal resolution was available for catches in traditional pitfalls (containing preservative), therefore these results are presented without statistical comparison.

\section{RESULTS}

\section{Mark-recapture abundance estimation}

In total 2,191 adult $P$. agrestis individuals were marked in survey $A$, and 3,165 in survey $B$. The sex ratio of the captured individuals was greatly different from equal, furthermore the direction of the bias was not consistent in the two surveys. The recapture rate was just under $20 \%$ for both sexes in survey $\mathrm{A}$, but it was much lower, $(3.6 \%$ for males and $6.1 \%$ for females) in survey B. The rate of repeated recaptures did not differ obviously from that of first recapture (Table 1). The majority of the recaptures occurred in a short period after the first catch. In the first survey more than $80 \%$, and in the second more than $57 \%$ of the recaptures occurred within 3 days following the previous capture event in both sexes.

Abundance estimation was performed using the $\mathrm{Mt}$ model. The choice of this model was necessitated by the temporal variability of captures (see below) and was supported by the results of the model selection procedure of the Capture program. Estimates from the Mt model were conservative, as compared to the estimates provided by

TABLE 1. Results of the two MR trapping sessions and parameter estimations obtained from the Mt model.

\begin{tabular}{ccccccc}
\hline Survey & Sex & Marked indiv. & Recaptures $^{\mathrm{a}}$ & Diam. of movement range $(\mathrm{m})^{\text {Trapping area }\left(\mathrm{m}^{2}\right)}$ & Population size $^{\mathrm{b}}$ \\
\hline A & males & 1,739 & $346,84,24,5,1$ & 7.84 & 762 & $1406 \pm 148.4$ \\
& females & 452 & $84,12,1$ & 8.78 & 812 & $662 \pm 161.2$ \\
B & males & 1,290 & 47,2 & 7.60 & 1401 & $6353 \pm 2868.0$ \\
& females & 1,875 & $114,12,2,1$ & 6.40 & 1316 & $5983 \pm 1627.7$ \\
\hline
\end{tabular}

\footnotetext{
${ }^{a}$ The number of $1,2, \ldots . \mathrm{n}$ times recaptured $P$. agrestis.
}

${ }^{\mathrm{b}}$ Values are weighted means $\pm \mathrm{SE}$. 
TABLE 2. Density and abundance estimates of male and female $P$. agrestis in the two surveys using three sampling techniques. Values are means $\pm \mathrm{SE}$.

\begin{tabular}{ccccc}
\hline Survey & Sex & MR density, indiv. $/ \mathrm{m}^{2}$ & Suction sampling density, indiv. $/ \mathrm{m}^{2}$ & Pitfalls with preservative, indiv./trap/day \\
\hline A & males & $1.85 \pm 0.194$ & $0.56 \pm 0.320$ & $0.72 \pm 0.120$ \\
& females & $0.81 \pm 0.198$ & $0.85 \pm 0.049$ & $0.15 \pm 0.025$ \\
B & males & $4.54 \pm 2.047$ & $1.92 \pm 1.110$ & $2.51 \pm 0.399$ \\
& females & $4.55 \pm 1.236$ & $0.64 \pm 0.370$ & $1.03 \pm 0.271$ \\
\hline
\end{tabular}

other models. Taking into consideration the results of the closure test, we estimated spider abundances for 3 day time windows. Time windows started on every other day (1st, 3rd, etc.), and therefore they partially overlapped. The weighted means of the estimated abundances are presented in Table 1.

\section{Mark-recapture density estimation}

To determine the total area for which the pitfall grid gave the estimated abundances, the movement range of the animals was assessed. In all cases there was a positive correlation between the length of time until recapture and the distance moved. The difference between the distances moved by males and females was significant only in the first survey (ANCOVA for survey A, effect of time: $F_{1,572}=37.15, P<0.0001$; effect of sex: $F_{1,572}=6.34$, $P<0.05$; ANCOVA for survey $\mathrm{B}$, effect of time: $F_{1,174}=19.01, P<0.0001$; effect of sex: $\left.F_{1,174}=0.45, \mathrm{NS}\right)$. From the fitted regression line between recapture time and distance we calculated the expected distances moved during 3 days, which proved to be similar in both years and for both sexes (Fig. 1, Table 1).
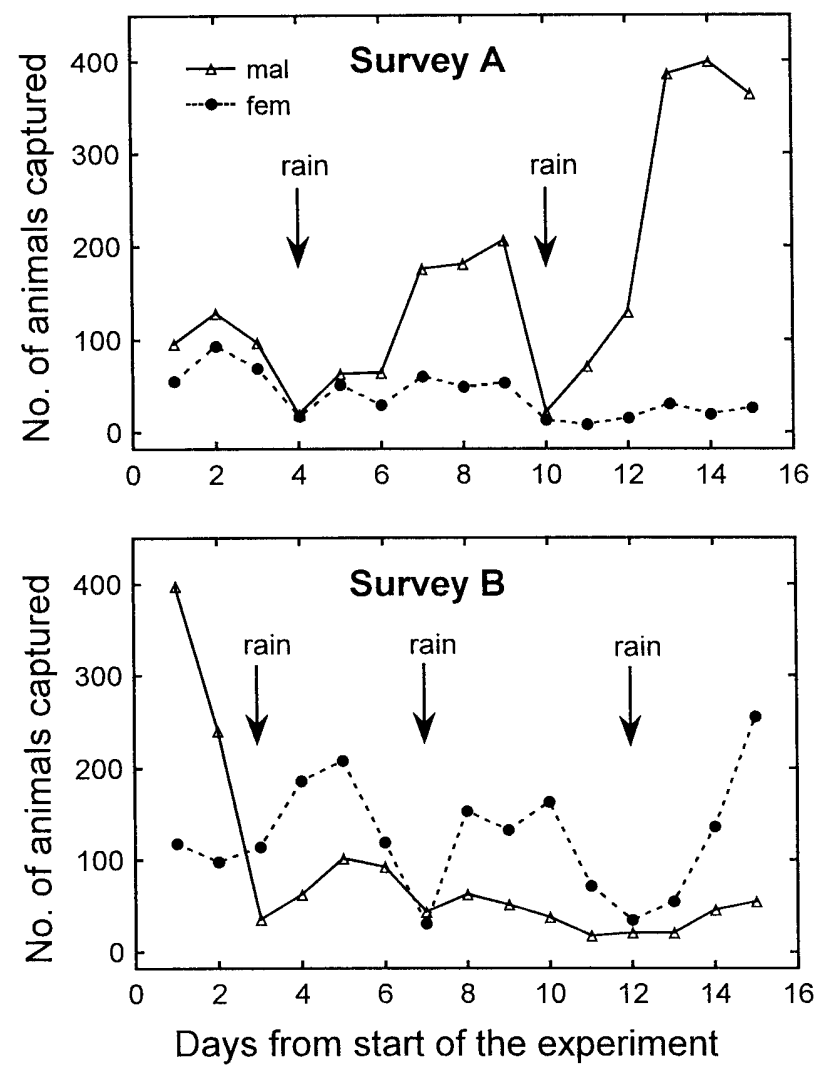

Fig. 2. Temporal variation in the total number of male and female $P$. agrestis caught in the two surveys. Days were counted from the first day of the survey.
Population density was obtained by dividing abundance estimates by the total sampling area. This area consisted of the area of the pitfall grid plus a border strip of the expected distances moved during 3 days, derived from the above calculations (Table 1). The weighted means of the estimated densities are shown in Table 2.

\section{Temporal variation of catches}

The number of the spiders caught daily was highly variable in both surveys, especially for males. The effect of rainy periods was noticeable in the catch results (Fig. 2). In the first survey, the recorded meteorological factors (daily minimum, maximum temperature, average wind speed, sunny hours, precipitation) had no significant effect on the number of females caught daily (stepwise multiple regression: adjusted $R^{2}=0.217$, d.f. $=12$, NS). On the other hand, the number of males caught daily was influenced by the daily minimum temperature and the precipitation (stepwise multiple regression: adjusted $R^{2}=0.729$, d.f $\left..=11, P<0.001\right)$. In survey B the number of females caught was influenced by precipitation (adjusted $R^{2}=0.44$, d.f. $=13, P<0.005$ ), and the number of males caught by daily minimum temperature and precipitation (adjusted $R^{2}=0.466$, d.f. $=12, P<0.01$ ).

\section{Comparison of sampling methods}

Using suction sampling a total of 682 and 791 spiders were collected in surveys A and B, out of which 1.0 and $1.4 \%$ were adult $P$. agrestis, respectively. Since data for suction sampling in Table 2 were based on 18 individuals of $P$. agrestis in total (both populations and both sexes), no statistical test is given for the comparison of this and the MR density estimating methods.

In neither year and for neither sex were significant correlations found between MR density estimates for the 3 day time windows and the corresponding catches by the live catching pitfall grid (Table 3 ).

TABLE 3. Comparison of live pitfall trap catches with derived MR density estimates using correlation analyses across the 3-day time windows.

\begin{tabular}{ccccc}
\hline Survey & Sex & $\mathrm{r}$ & $\mathrm{n}^{\mathrm{a}}$ & $\mathrm{P}$ \\
\hline $\mathrm{A}$ & males & 0.69 & 6 & 0.13 \\
& females & 0.52 & 4 & 0.47 \\
$\mathrm{~B}$ & males & 0.45 & 5 & 0.44 \\
& females & 0.50 & 6 & 0.12 \\
\hline
\end{tabular}

${ }^{a}$ Number of valid time windows used for the comparison.

\section{DISCUSSION}

In the present study we tried to answer the question of what population density might adult wolf spiders reach in alfalfa fields, by conducting two intensive mark-recapture 
surveys. We applied this method because the reliability of traditional density and abundance estimating methods, such as pitfall trapping and suction sampling, was questionable for studying population densities in wolf spider populations.

Pitfall trapping is a very efficient way of capturing wolf spiders, and its application has a long tradition in various faunistical and ecological studies (Loksa, 1966; Růžička, 1996). However, pitfall trap studies cannot provide a density estimation of the wolf spider populations, because the area from which the animals collected by a trap is not known (Southwood, 1978). Even for a given population of a particular species catches might vary with activity (Uetz \& Unzicker, 1976; Samu \& Sárospataki, 1995b, present study), and catchability can be radically different in various microclimatic and weather conditions, lifestages, and sexes (Honěk, 1988; Topping \& Sunderland, 1992; Samu et al., 1996b).

As opposed to pitfall trapping, suction sampling can provide an estimation of density, because catches can be related to the area over which the sampling has occurred. Although suction sampling has been found to be satisfactory for the density estimation of smaller and less active spiders (Sunderland \& Topping, 1993; Dinter, 1995), the case for lycosids appears to be different. In the study by Merrett \& Snazell (1983) comparing the efficiency of Dvac to pitfalls less than $1 \%$ of the total catch of Lycosidae was present in the D-vac samples, the rest having been caught in pitfalls, while for all spiders this ratio was approximately $50 \%$. Suction sampling is likely to be inefficient for lycosids because of their high mobility. They can escape from the suction apparatus (Yeargan \& Cothran, 1974a), flee from the sampling area on the approach of the investigator (Samu et al., 1997), or hide in soil fissures (Yeargan \& Cothran, 1974b). This behaviour has also rendered the application of suction sampling in fenced quadrates inappropriate for the density estimation of wolf spiders (Dinter, 1995; Samu et al., 1997).

Mark-recapture methods are known to be applicable for the estimation of density and demographic parameters of various animal populations (Crist \& Wiens, 1995; Szép, 1995). MR models are based on specific assumptions (Otis et al., 1978), and the present study helped to identify the applicability of these to wolf spider populations. The assumptions of the MR model used includes the permanency of marks and their correct recording at each trapping occasion. Marking by enamel paint proved to be permanent in previous field studies for lycosid (Greenstone, 1979), and linyphiid spiders (Samu et al., 1996a). On the other hand, painting can be reliably applied to adults only, because juveniles lose the mark through moulting. Because of the high locomotory activity of Pardosa species (Baatrup \& Bayley, 1992), the assumption of population closure can be a critical point in MR studies concerning these spiders. Individual marking and recording of recaptures in the trap grid allowed us to follow the displacement of multiply-recaptured individuals. With a daily displacement of 4-8 m, P. agrestis individuals were likely to leave the area of the grid within the duration of the study. On the other hand a trap distance of about half of the daily displacement secured acceptable recapture rates. The applied statistical tests showed that closure held for about 3 days in the wolf spider populations at the scale of the study. To increase the area covered by the trapping grid of the above resolution in the present study would have required unmanageably high trap numbers. Wolf spiders have large movement ranges. Therefore to obtain reliable density estimates, relatively high recapture rates are desirable, so any MR studies on lycosids will require intensive sampling over a comparatively large area.

Given the above reasons, MR studies of wolf spiders cannot be recommended as a regular tool for field ecologists, although comparisons with other sampling methods can be useful in interpreting results obtained by these techniques (Greenstone, 1979). As compared to MR estimates, suction sampling tended to produce somewhat lower density figures. These density estimations cannot be considered statistically representative, because they were based on very few specimens. Much larger sample sizes would have been required to obtain adequate density estimation by suction sampling. In contrast to the low catches of Lycosidae, suction sampling with the same effort (our "usual" sampling effort) produces orders of magnitude higher catches from most other spider families.

There was an obvious inconsistency between the two surveys concerning sex ratios in live trapping pitfall trap catches. We think that the two sexes to some degree responded differently to some unknown factor. Therefore it is possible that male catchability, even relative to that of females, was different between the two surveys.

Comparison of live catching pitfall trapping with derived MR density estimates revealed no significant correlation for short duration trapping, probably because of the high daily variability of the catches. For 15 day catches with pitfalls with preservative daily variation is likely to be averaged. However, for this longer term data we had only 2 data points for each sex, which allowed us only to observe that for both sexes higher pitfall catches corresponded to higher MR density estimates. Perhaps more extensive series of MR surveys would produce a true calibration of pitfall trap catches for a few selected species of generalist predators.

Mark-recapture studies are useful in estimating densities for mobile predatory arthropod groups, for which such estimates are scarce in the literature (Sunderland et al., 1995). From the present results a conservative estimate of the density of $P$. agrestis in the study fields was close to 2 males and 1 females per $\mathrm{m}^{2}$ in the first, and 4.5 males and 4.5 females per $\mathrm{m}^{2}$ in the second experimental site. Since in August a second peak of females carries cocoons and young (as many as 60 spiderlings per female), juvenile spiders comprise numerically the greatest proportion of the wolf spider population (Samu et al., 1998). Extrapolating this will result in a total $P$. agrestis density being several times the adult density. If only adult densities are considered, the estimates gave very considerable numbers for a relatively large and widely-foraging arthropod predator species. Densities, of course, may vary with 
time and location, but we believe that having an estimate of the order of magnitude of wolf spider densities may help to evaluate their role in agroecosystems.

ACKNOWLEDGEMENTS. We are grateful for the technical assistance of E. Botos. We thank L. Nemesvári, I. Fábián and G Vörös who made the use of one of the alfalfa fields possible. The study was funded by the British Ecological Society Smal Ecological Project Grant (No. 1320) and OTKA (grant No. F 23627). F. Samu was a Bolyai Fellow of the Hungarian Academy of Sciences.

\section{REFERENCES}

BAATRUP E. \& BAYLEY M. 1993: Quantitative analysis of spider locomotion employing computer-automated video tracking. Physiol. Behav. 54: 83-90.

CRIST T.O. \& WIENS J.A. 1995: Individual movements and estimation of population size in darkling beetles (Coleoptera: Tenebrionidae). J. Anim. Ecol. 64: 733-746.

DinTER A. 1995: Estimation of epigeic spider population densities using an intensive D-vac sampling technique and comparison with pitfall trap catches in winter wheat. Acta Jutl. 70: $23-32$.

DUFFEY E. 1980: The efficiency of the dietrick vacuum sampler (D-vac) for invertebrate population studies in different types of grassland. Bull. Ecol. 11: 421-431.

Ford M.J. 1978: Locomotory activity and the predation strategy of the wolf spider Pardosa amentata (Clerck) (Lycosidae). Anim. Behav. 26: 31-35.

Greenstone M.H. 1979: A line transect density index for wolf spiders (Pardosa spp.) and a note on the applicability of catch per unit effort methods to entomological studies. Ecol. Entomol. 4: 23-29.

HoNĚK A. 1988: The effect of crop density and microclimate on pitfall trap catches of Carabidae, Staphylinidae and Lycosidae in cereal fields. Pedobiologia 32: 233-242.

LOKSA I. 1966: Die bodenzoozönologischen Verhältnisse der Flaumeichen-Buschwälder Südostmitteleuropas. Akadémiai Kiadó, Budapest, 437 pp.

MerRett P. \& SNazell R. 1983: A comparison of pitfall trapping and vacuum sampling for assessing spider faunas on heathland at Ashdown Forest, south-east England. Bull. Br. Arachnol. Soc. 6: 1-13.

Otis D.L., Burnham G.C., White G.C. \& Anderson D.R. 1978 Statistical inference from capture data on closed populations. Wildl. Monogr. 62: 1-135.

RƯžIČKA V. 1996: Species composition and site distribution of spiders (Araneae) in a gneiss massif in the Dyje river valley. Rev. Suisse Zool. hors série: 561-569.

SAmu F. \& Sárospataki M. 1995a: Design and use of a handhold suction sampler and its comparison with sweep net and pitfall trap sampling. Folia Entomol. Hung. 56: 195-203.

SAMU F. \& SÁrospatakI M. 1995b: Estimation of population sizes and home ranges of polyphagous predators in alfalfa using mark-recapture: an exploratory study. Acta Jutl. 70: $47-55$.
SAmu F., Németh J. \& Kiss B. 1997: Assessment of the efficiency of a hand-held suction device for sampling spiders: improved density estimation or oversampling? Ann. Appl. Biol. 130: 371-378.

Samu F., Sunderland K.D., Topping C.J. \& Fenlon J.S. 1996a: A spider population in flux: selection and abandonment of artificial web-sites and the importance of intraspecific interactions in Lepthyphantes tenuis (Araneae: Linyphiidae) in wheat. Oecologia 106: 228-239.

SAMU F., Vörös G. \& Botos E. 1996b: Diversity and community structure of spiders of alfalfa fields and grassy field margins in South Hungary. Acta Phytopathol. Entomol. Hung. 31: 253-266.

Samu F., Németh J., Tóth F., Szita É., Kiss B. \& Szinetár C. 1998: Are two cohorts responsible for bimodal life history pattern in the wolf spider Pardosa agrestis in Hungary? In Selden P.A. (ed.): Proceedings 17th European Colloquium of Arachnology. British Arachnological Society, Edinburgh, pp. 215-221.

Samu F., Tóth F., SzInetár C., Vörös G. \& Botos E. 2000: Results of a nation-wide survey of spider assemblages in Hungarian cereal fields. IOBC/WPRS Bull. (in press).

SEBer G.A.F. 1982: The Estimation of Animal Abundance. Griffin, London, $654 \mathrm{pp}$.

Southwood T.R.E. 1978: Ecological Methods with Particular Reference to the Study of Insect Populations. Methuen, London, $391 \mathrm{pp}$.

SUNDERLAND K.D. \& TopPING C.J. 1993: The spatial dynamics of linyphiid spiders in winter wheat. Mem. $Q d$ Mus. 33: 639-644.

Sunderland K.D. \& Topping C.J. 1995: Estimating population densities of spiders in cereals. Acta Jutl. 70: 13-22.

Sunderland K.D., De Soono G.R., Dinter A., Hance T., HeLentus J., Jepson P., Kromp B., SAMu F., Sotherton N.W., UlBER B. \& TOFT S. 1995: Density estimation for invertebrate predators in agroecosystems. Acta Jutl. 70: 133-162.

SzÉP T. 1995: Survival rates of Hungarian sand martins and their relationship with Sahel rainfall. J. Appl. Stat. 22: 891-904.

TopPING C.J. \& SunderLand K.D. 1992: Limitations to the use of pitfall traps in ecological studies, exemplified by a study of spiders in a field of winter wheat. J. Appl. Ecol. 29: 485-491.

То́тн F. \& Kiss J. 1997: Occurrence of Pardosa (Araneae, Lycosidae) species in winter wheat and in the field margin. In Zabka M. (ed.): Proceedings of the 16th European Colloquium of Arachnology. Siedlce, pp. 309-315.

Uetz G.W. \& Unzicker J.D. 1976: Pitfall trapping in ecological studies of wandering spiders. J. Arachnol. 3: 101-111.

White G.C., Anderson D.R., Burnham K.P. \& Otis D.L. 1982 : Capture-Recapture and Removal Methods. Los Alamos National Laboratory, Los Alamos, $235 \mathrm{pp}$.

YeARGAN K. \& Cothran W. 1974a: An escape barrier for improved suction sampling of Pardosa ramulosa and Nabis spp. populations in alfalfa. Envir. Entomol. 3: 189-191.

Yeargan K. \& Cothran W. 1974b: Population studies of Pardosa ramulosa (McCook) and other common spider in alfalfa. Envir. Entomol. 3: 989-993.

Received May 7, 1999; accepted January 4, 2000 